\title{
LA TERAPÉUTICA ESTOICA CON LA VEJEZ
}

Ricardo Iacub*

\section{Resumen}

El estoicismo nuevo produjo una vasta teoría para pensar la vejez desde un ángulo positivo, y desafiante a las consideraciones de su época. La misma ha dado lugar a un estilo de vida en la vejez, denominado retiro Ciceroniano, y produjo un tipo de terapéutica que definió un síntoma y un modo de alivio para afrontar los cambios que supone el proceso del envejecimiento. La investigación se basa en fuentes literarias, filosóficas e históricas.

Palabras claves: Vejez. Estoicismo. Terapéutica.

\section{Introducción}

A través de la revisión de la temática de la vejez, al interior del edificio doctrinal estoico, se intentará demostrar que el espacio valorado que cobró la primera, no resultó de las condiciones sociales e históricas de esa época, sino de una propuesta terapéutica para enfrentar esta etapa vital.

La importancia que cobró este pensamiento trasciende en mucho una época, ya que la reflexión estoica sobre la vejez ha sido una marca cultural positiva a lo largo de la historia para indicar un estilo de vida en este etapa vital, al que se lo denominó “[ . . . ] retiro ciceroniano.” (TROYANSKY, 1992, p. 93).

Se introducirá este desarrollo presentando los diferentes conceptos que darán cuenta del estoicismo, y que permitirán concebir la forma en que estos ubicaron la problemática de la vejez.

Los autores que se utilizaron para este análisis corresponden al estoicismo nuevo, entre ellos: Epicteto, Séneca, Cicerón y Marco Aurelio. Filósofos que comparten, en gran medida, argumentaciones comunes acerca de la vejez, aunque surgen diferencias al interior de sus obras.

\footnotetext{
* Licenciado en Psicología. Profesor de grado y posgrado en Psicogerontología en la Universidad de Buenos Aires y la Fundación Universitaria Isalud. Investigador del grupo de Socioantropología de la Vejez y Planificación Comunitaria del Envejecimiento (SAVIPCE), de la Universidad de Mar del Plata y del Centro de Investigaciones en Derecho de la Ancianidad, Universidad de Rosario. E-mail: riacub@fibertel.com.ar
} 


\section{Teoría del valor: noción del Bien}

La tesis radical que sostiene la teoría estoica es: "[... ] solo lo que tiene valor moral es bueno [ . . . ]"(ENGBERG-PEDERSEN, 2001, p. 153) y aporta felicidad. La lógica que prosigue es la siguiente: el valor, lo noble, produce felicidad. La virtud es un bien intrínseco, el más alto, por ello es el componente esencial de la felicidad. Concepción de la virtud que no reconoce los fines mixtos como para Platón y Aristóteles.

Por otra parte la noción de bien concuerda con la naturaleza del hombre que es distinta de los bienes naturales como la salud.

\section{Vivir de acuerdo a la naturaleza}

El vivir de acuerdo a la naturaleza se considera el supremo bien, que es el de poseer y hacer propia la ciencia de lo que conforma a la naturaleza. El hombre es el único de los seres que comparte la racionalidad de la misma. La armonía que resulte dará cuenta de la felicidad conseguida. Este tipo de naturalismo solo alcanzado por la razón humana abre una hiancia entre lo humano y lo animal; y en lo humano y lo que hay en el de animal. Así como también definirá el bien como lo útil, pero en tanto consecuente. Lo útil es lo que oriente el sentido de la vida, tanto a nivel del destino como la voluntad de Dios. Para Diógenes, el estoico, lo útil sigue el principio, un movimiento o un estado en armonía con el bien perfecto de la naturaleza.

Desde este naturalismo se pueden establecer distinciones entre las cosas existentes: unas son bienes como la reflexión, justicia, coraje, sabiduría; otras son males como la irreflexión, injusticia, cobardía; otras indiferentes como la vida, muerte, salud, enfermedad, placer, dolor, belleza, etc. Son indiferentes porque, en si mismas, ni nos sirven ni nos dañan.

El bien es equiparable a la belleza, en tanto alude a una armonía interior que se identifica a la armonía del mundo. La belleza del bien es la expresión del concierto providencial de las cosas y los seres.

La virtud es la presencia del bien en una persona, que dará por resultado que el círculo de la naturaleza se presentifique en el hombre.

La visión teleológica de los estoicos es descripta por EngbergPedersen (2001, p. 154) de este modo: 
a) que todo ocurre según el plan providencial de la naturaleza; b) que el hombre mantiene una relación especial con la naturaleza pues solo el (único entre los animales) comparte su racionalidad; c) que los llamados bienes externos carecen de valor; d) que al hombre deben importarle los demás, ya que pertenece con ellos a una comunidad especial.

Entonces, si los hombres son los únicos capaces en captar la racionalidad de la naturaleza, son por ello los únicos en obedecer su voluntad, y por ejercerla son los únicos que pueden ser virtuosos. Desde aquí, entonces, se enlaza la noción de voluntad o deseo que queda expresado por Epicteto (1919, p. 43) de esta manera:

[ . . . ] siempre prefiero lo que sucede, porque estoy persuadido de lo que los Dioses quieren es mejor para mí que lo que yo quisiera. A ellos pues me confío, a ellos obedezco y a ellos someto mis deseos, mis movimientos, mis voluntades, mis temores. En una palabra; quiero lo que ellos quieren $[\ldots]$.

La razón de este sometimiento de la voluntad es en razón de una bondad de la naturaleza a través de la cual emerge el bien humano.

Cicerón (1961) sostenía que las cosas eran estimables si estaban de acuerdo a la naturaleza, ya se por producir algo natural o por tener cierto valor natural; mientras que resultaban despreciables cuando contenían caracteres opuestos a los anteriores. El primer deber del estoico sería ligar lo que es conforme a esa naturaleza y separar lo que le es contrario.

Es importante para entender este concepto, eje de la doctrina, pensar como fue comprendida esta noción de naturaleza. Si el hombre la aprehende a través de su razonamiento es porque ella misma es razón, así como Dios también lo es, según Epicteto (1950). Idea de naturaleza homologable al raciocinio, de lo que se desprende una noción de sujeto o sí mismo, pensado desde esta perspectiva intelectual.

Este tema es complejo dentro de la moral estoica, ya que la opinión de Epicteto puede resultar lejana a la de Cicerón. Este último es un autor controversial, ya que trata de no extremar las posiciones de esta doctrina, limando sus radicalizaciones. Ejemplo de ello es que Cicerón afirma que hay un valor natural en la noción de si mismo y que pueden ser valiosas las que 
mantengan una relación fáctica con ella (como la salud o el conocimiento). Sin embargo esta acepción podría ser discutible en otros autores y en otros escritos del propio autor, especialmente en lo que se refiere a darle igual valor a la salud que al conocimiento. La insistencia en tales diferenciaciones es porque resultan de importancia para realizar la interrelación entre la vejez y el estoicismo. Por ello también, todas estas temáticas serán retomadas en distintos puntos de este trabajo.

Cicerón, ${ }^{1}$ según Engberg-Pedersen, consideraba que existía desde el nacimiento un apego y un mandamiento a amarse y preservarse a si mismo al tiempo que el sujeto alberga antipatía por aquello que pueda destruirlo.

Esta consideración resulta controversial al interior del estoicismo, ya que el apego o preservación de si no tendrá el mismo sentido en los diversos autores. Cicerón puede comprender la constitución física como parte de este sentido de si, mientras que para Epicteto o Séneca, la representación de si es eminentemente intelectual. Epicteto lo ubica como un primer exterior y Séneca (1955a) apelaba al suicidio si la preservación del si mismo lo reclama.

Sobre esta temática creo que es importante deslindar las posiciones ontológicas sobre la noción de cuerpo y alma, y las cuestiones éticas que derivan en cuestiones teóricas diferenciales.

\section{Noción de cuerpo y alma}

El cuerpo para los estoicos se compone de carne a través de la cual se ha expandido el alma, razón por la cual se diferenciaría de otros bienes. Sin embargo, para Epicteto, es lo que compartimos con los animales. El mismo autor, en sus Máximas (1919, p. 52) refiere dos naturalezas perfectamente distintas: el parentesco a las fieras que lo consideraba "[... ] desgraciado y muerto", mientras que el del espíritu "[ ... ] feliz y divino."

El cuerpo para este filósofo no termina de espiritualizarse, y por ello lo considera una carne enfermiza y miserable. El alma, en cambio, fue pensada como un pneuma ígneo que se expande continuamente a través del cuerpo, mientras siga recibiendo la respiración normal de la vida. Esta se halla distribuida en tantas regiones como partes tiene el organismo, la región del alma en que todas las partes se concentran es el corazón, resultando evidente la dificultad, dentro de la doctrina, de conciliar estos conceptos.

${ }^{1}$ CICERÓN, Marco Túlio. Finibus bonorum et malorum. Libor III. Trad. Rackham. Roma: Moricca, 1931. P. 16-18; 20-21. Apud ENGBERG-PEDERSEN, 2001, p. 156. 
Desde la noción de desapego se vuelve a introducir esta problemática. El sabio estoico otorga una fuerte valorización al si mismo, el cual se asemeja a nuestra concepción de lo psíquico. Cicerón critica la noción de desapego con la que se manejan los estoicos de su época considerando que, aunque los filósofos dividan la naturaleza del hombre en alma y cuerpo y consideren a cada una apetecible de por si, al declarar la excelencia del alma infinitamente superior a la del cuerpo, anteponen las virtudes del alma sobre los bienes corporales.

El prescindir de los bienes del cuerpo, es comentado por Epicteto (1950, p. 36) de este modo: “[ ... ¿ ¿Qué cosa más perversa, más intolerable, más necia, que poner entre los bienes la salud y la carencia de dolor, la integridad de los ojos y de los demás sentidos, en vez de decir que no hay diferencia alguna entre estas cosas y sus contrarias? [... ].” Este filósofo le va dando al cuerpo formas particulares: "[ ... ] En realidad, no lo olvides, este cuerpo no es propiamente tuyo, no es mas que tierra hábilmente amasada [...]." (1950, p. 42).

Desde este bien, el cuerpo, Epicteto (1950, p. 43) hace derivar los otros bienes, y bajo un modo de enlace, que él llama "encadenamiento", a hijos, amigos, fortuna, establecía que es a raíz de este lazo que quedamos limitados y " [... ] tiran nuestros pies hacia abajo." Esta falta de libertad vuelve débiles y esclavos a los hombres, lo adjudica al sujetarse a bienes extraños. "El verdadero bien, dirá el mismo filósofo, será lo que dependa de ti." (EPICTETO,1950, p. 44). En este sentido Séneca consideraba que “[ ... ] el amor a la vida es la única cadena que nos tiene atados." (1955b, p. 90).

\section{Enfermedad y muerte}

Al leer a los estoicos aparece una preocupación fundamental, que es enfrentar la enfermedad y la muerte, razón por la cual resulta frecuente encontrar referencias, casi continuas, en sus textos a dichas temáticas.

El objetivo es articular estos conceptos desde la noción de bien (que en parte ya fue esbozada) y por el lado de las pasiones. La definición permanente acerca de la enfermedad y la muerte es que son objetos indiferentes. Lo que daría cuenta que el valor no está dado por el objeto en sí, sino la opinión sobre la misma. Uno de los ejemplos más interesantes se encuentra en Cicerón (1961) cuando ubica la cantidad de dolor en proporción 
a la importancia de la causa. Lo cual indicaría el peso del saber u opinión en la construcción de dicha sensación.

El saber, dice Cicerón (1961), es siempre feliz, por lo tanto en su relación al dolor, este se atemperará con relación al saber del sabio. Siendo el dolor un tipo de bien, ni bueno ni malo, en tanto no hay en el " [ ... ] ni engaño, ni malicia, ni culpa, ni torpeza" (EPICTETO, 1950, p. 44) a pesar de que sea “[ ... ] áspero, molesto, odioso." (EPICTETO, 1950, p. 44).

La insistencia en la noción de uso del bien, y no de la calificación moral del mismo, ha sido una constante fuente de discusión con los peripatéticos.

Epicteto, a través de la noción de voluntad, tiende a destituir toda entificación de lo que es nuestro bien o nuestro mal, lo que implicaba que: “[ ... ] la enfermedad es un obstáculo para el cuerpo, pero nunca para la voluntad, a menos que ella quiera."(EPICTETO, 1919, p. 66).

\section{Las pasiones}

La pasión no es una pasividad sino un movimiento irracional del alma, contraria a la naturaleza, o una tendencia sin moderación (BRUN, 1968). Las definiciones aparecen del lado de lo contrario a la razón, más ligado al falso juicio o a la falsa creencia. Obviamente la concepción será intelectualista, como locura o irracionalidad, donde sólo la razón puede liberarnos de las pasiones.

Para Brun (1968) algunas de las pasiones más destacadas son: el dolor, el miedo, el deseo sensual y el placer. Cada una de estos conlleva a otras, por ej. el temor, como espera de un mal, produce duda espanto, angustia, etc. Las pasiones son concebidas como enfermedades del alma, o sea, que desde esta consideración, la posición temerosa o de angustia de un individuo frente a los ejes enfermedad y muerte podrá ser comprendida como una pasión, una enfermedad, un falso juicio, cuyo remedio será la razón. Marco Aurelio (1987, p. 125) lo expresaba de este modo:

¡Cómo en un instante desaparece todo: en el mundo, los cuerpos mismos; y en el tiempo su memoria! ¡Cómo es todo lo sensible, y especialmente lo que nos seduce por placer o nos asusta por dolor o lo que nos hace gritar por orgullo! ¡Cómo todo es vil despreciable, sucio, fácilmente destructible y cadáver! Eso debe considerar la facultad 
de la inteligencia. ¿Qué son esos, cuyas definiciones y palabras procuran buena fama y deshonor?, ¿Qué es la muerte?, Porque si se la mira a ella exclusivamente y se abstraen por división de su concepto, los fantasmas que la recubren, ya no sugerirá otra cosa sino que es obra de la naturaleza.

Siendo su obra ya no habrá que temerla y si aceptarla como tal, porque es útil al ciclo de generación y corrupción. O sea, a través de una debida sumisión al tiempo, al conocimiento de lo necesario. Para ello la sabiduría, no la pasión.

\section{La vejez: una articulación}

Cicerón plasma, en su obra De Senectute, claramente basada en Platón, el anudamiento literario entre la obra estoica y la temática de la vejez. Sin embargo no es la única obra que se refiera a la temática, aunque si haya quedado en el registro de Occidente como un modo posible de envejecimiento asociado al nombre de Cicerón.

En este texto se realiza una argumentación brillante y moderna acerca de las posibilidades de la vejez al tiempo que aminora o neutraliza sus defectos o limitaciones.

El personaje viejo es nada menos que Catón, quien con 84 años responde a una serie de preguntas que le realiza Escipión. Una de estas, probablemente la más importante en el marco de este texto, es acerca del porque la vejez no implica para él una molestia, mientras que para otros les es tan odiosa.

Para ello Catón recurre a una concepción clásica estoica:

[ . . ] porque a aquellos que en sí mismos no tienen los medios para vivir bien y felizmente, cualquier edad les es pesada; a los que buscan todos los bienes en si mismos, a éstos no puede parecerles malo todo aquello que la necesidad de la naturaleza traiga. Y precisamente en esta clase se encuentra en primer plano la vejez; a la cual todos desean llegar y, al llegar todas la acusan. ¡Tanta es la inconstancia y lo absurdo de tanta extravagancia! (CICERÓN, 1982,p. 98). 
En esta primera cita se pueden desprender diversos conceptos. Por un lado la dependencia de los bienes (en esta traducción la idea de bienes es tomada como objetos, no referida a su dimensión valorativa) que ubica en todas las edades, a diferencia del que mira su interior, o sea el sabio, que no depende de lo externo. Por otra parte la noción de "necesidad de la naturaleza" concebida como un vivir en armonía aceptando de buen grado lo que ella trae consigo, aparece como un recurso frente a la imprevisión y falta de perspectiva de los necios.

El estoico se arma de sabiduría para enfrentar lo que la naturaleza les presenta. Epicteto lo refiere de este modo:

Yo procuraré, pues, imitar a este gran modelo. Me verás lleno de fidelidad, de pudor, de valor, inaccesible a las zozobras y emociones que causan lo que llamamos accidentes terribles. Pero dirás ¿serás por ello inmortal?, ¿te verás libre de la ancianidad y de las enfermedades?, no, pero verás como saber morir y estar enfermo y envejecer, verás que un filósofo tiene los nervios bien templados. (EPICTETO, 1950, p. 77).

Entonces frente al padecer humano, a causa de objetos que para la doctrina son indiferentes, el sabio se reviste de la filosofía como de una muralla ante la cuál se prueba el verdadero estoico.

Honores monumentos, todo lo que la ambición ha
ordenado con decretos o ha elevado con su esfuerzo, se
desploma rápidamente, nada deja de demoler y transformar
la prolongada vejez. En cambio, no puede dañar aquello
que consagró la sabiduría; ninguna edad acabará con ella,
ninguna le quitará nada. (SÉNECA,1997, p. 341).

Es así como el autor sostiene la conservación y a su vez la consagración de este bien ineliminable, la sabiduría, como un medio de enfrentar esta serie de pérdidas con que se concibe a la vejez. Pero también nos remite a la noción de tiempo como edad y en su dimensión de acto. Esta relativización del tiempo Marco Aurelio lo describe como "[ ... ] un punto" y como una “[ .... ] sustancia fluyente.”(1987, p. 122). La noción de punto tiende a diluir la idea de edad por la noción de día, un día que huye pero en el cuál el individuo es responsable de hacer lo propio y desde allí, incorporar 
tiempo o vivir. Por ello Séneca modifica y subjetiva la noción de tiempo a través de esta frase: "¿Quieres saber cuan poco viven? Observa como desean vivir mucho." (1997, p. 331).

El uso del tiempo presente es fundamental para aprovechar lo que Séneca denomina vivir. El futuro como expectativa, sólo enturbia esta capacidad del presente. Por otro lado vivimos entre dos muertes: el pasado y la que nos espera en el futuro; la experiencia vital resurge en la noción de Cicerón (1961) de un mejor día, ya que es el único tiempo que se le quita a la muerte. Es por ello que la meditación sobre la muerte, especialmente en Séneca, agrupa una serie de sentidos ligados al tiempo y a la libertad sobre los bienes que incidirán profundamente en el sentido moral que propugna su obra.

Por último, el filósofo refleja el sentido antes citado con esta pregunta: “¿Qué es lo principal en la virtud? No sentir necesidad del tiempo futuro, ni contar sus días. Por breve que sea un tiempo puedes realizar en él bienes eternos." (SÉNECA, 1955c, p. 98).

\section{El cuerpo y la vejez}

Tras haber desarrollado la noción del cuerpo para los estoicos y ciertas nociones sobre la vejez, quisiera enlazar la noción de cuerpo con la de vejez, ya que desde una perspectiva greco romana, existió una desvalorización del cuerpo de los viejos, con frecuentes referencias a una desidentificación progresiva (IACUB, 2004) con excepciones como la de Platón, que influenció esta corriente filosófica.

Si por un lado hay un amor innato al cuerpo en la doctrina, es un amor que se debe a una necesidad, pero ante la cual, siempre está el peligro de caer en la dependencia. Esta carne espiritualizada, que en algunos filósofos no termina por hacer-se cuerpo, como mencionábamos anteriormente, se configura más como aquél que puede privarnos de libertades. Privación que remite a un sujeto o "si mismo" que no es totalmente equivalente a su cuerpo. En este sentido se rescata la vejez como momento vital, ya que los bienes corporales que pueden perderse por la edad no incidirán en la felicidad porque estos carecen de valor intrínseco. Por el contrario, la estrategia estoica es pensar la vejez como un momento en el cual el sujeto se confronta con una falta que probaría la consistencia del sabio y que por otro lado permitiría deshacerse de la pesada carga que el cuerpo le produce al alma. 
Séneca nos permite acercarnos a esta estrategia a través de la articulación entre el cuerpo y las pasiones. En la Carta "Ventajas de la Vejez" (1955b, p. 40) dice: “¡Cuán dulce es haber fatigado y abandonado los deseos!" en donde superadas las pasiones y no habiendo necesidad de los placeres, se podría disfrutar las delicias o dulzuras de la vejez, abriendo un espacio donde existiría un tipo de placer que queda asociado a las pasiones físicas y otro, que considera aun mayor, ligado a un placer más refinado o suavizado y en cierto sentido más racional, que toma el lugar del placer pasional.

En otra epístola "El encanto de la vejez y la preparación para la muerte", señala:

El alma está vigorosa y se alegra de no tener mucha comunicación con el cuerpo. Se ha despojado de gran parte de su carga. Salta de gozo y me plantea la discusión sobre la vejez: afirma que ésta constituye su esplendor. Otorguémosle crédito, que disfrute de su propio bien. (SÉNECA, 2000, p. 207).

Esta frase resulta particularmente llamativa y no deja de provocar dudas acerca de su intención. En principio esta escisión tiene como fin pensar al sujeto socialmente situado a diferencia del alma, y es por ello que se plantea una discusión y no una aseveración, lo que determinaría que el "hay que" dar crédito aparece como un afirmación no del todo evidente y más bien surge como un imperativo de aceptación del esplendor de la vejez. Curiosamente el nombre de esta epístola da cuenta de una ética en donde el sujeto hace frente ante la pérdida de goces corporales, la declinación y la muerte como si fuesen elecciones racionales, buscando acompañar la razón de la naturaleza.

\section{Las practicas de sí}

Consecuentemente con este edificio doctrinal estoico, existían practicas de si propias de las diversas escuelas filosóficas que tendían hacia la terapéutica, es decir que la filosofía antigua estaba asociada a lo que hoy podríamos considerar la cura espiritual o mental.

Foucault (2002) evidencia un cambio en estas prácticas que evolucionaron de ser formadoras de adolescentes; a ser, entre los estoicos y los epicúreos, practicas formadoras, pero a su vez criticas, agregaría reflexivas, 
que se implementaban en cualquier edad pero que tenían su punto sensible en la adultez tardía. Una de las transformaciones más interesantes es la del consejero personal cuyo objetivo no era estrictamente pedagógico, sino ser un consejero de la existencia.

Este modo de relación buscaba un contacto más profundo, lo que los epicúreos consideraban una apertura de corazón, donde no había que ocultarse nada, dando lugar a una dirección de la consciencia que promovía el conocimiento de si o la preocupación de si (FOUCAULT, 2002).

Séneca consideraba que lo malo nunca estaba tan incrustado en el hombre como para que no pueda ser modificado. Utiliza la frase: "Has de aprender la manera de vivir mientras vivas." (SÉNECA, 1955d, p. 257). Esta preparación implicaba que el hombre debía realizar un cambio, un aprendizaje sostenido desde la crítica y la reflexión sobre sí mismo.

Séneca extremó esta idea al punto de convertir a la vejez en un objetivo positivo de la existencia, polarizando con sus propios valores todo el curso de la vida. La que, de esta manera, será pensada en una pieza: "[ . . . ] vivir para ser viejos", llevándolo a criticar los cortes en las etapas vitales, por que limitaban el sentido de totalidad de la existencia (FOUCAULT, 2002, p. 117). Totalidad que permitiría mantener un objetivo y no perderse en las múltiples alternativas que aparecen en la vida.

Esta ética proponía vivir la vida como ya habiéndola vivido, tratando con ello de restarnos inocencia, duda o ansiedad. Para eso haría falta la sapiencia, para no errar y confundirnos, y la ataraxia, en tanto goce consigo mismo o con los bienes internos, que permitan apaciguar la búsqueda desenfrenada de las pasiones personales o de los objetos externos. Esta "búsqueda desenfrenada", Séneca la calificaba como la Estulticia (stultitia), agitación del pensamiento o necedad. El estulto (stultus) estaría abierto a todos los vientos, disperso en el tiempo, desparramándose sin memoria ni voluntad, sin saber aplazar sus pasiones. En este punto no tendría libertad ya que esta resulta de la voluntad y el manejo sobre sí, la cual permitiría una serenidad ante el desenfreno que pueden producir los objetos propios de las pasiones. La sapiencia, es decir el conocimiento, posibilitaría el manejo de si, a través de una voluntad soberana que volvería libre al sujeto. Séneca consideraba que "[... ] la estulticia podía remontarse a la sabiduría pero la sabiduría no puede rodar a la estulticia.” (1955d, p. 260).

Entre la ataraxia, la sapiencia y la estulticia hallamos las coordenadas desde donde el estoico plantea la posición ética ante la vida, posición que la 
vejez, por las razones antes mencionadas, precipita al tiempo que posibilita. Dando un rango de ventaja que se conseguirá a través de una posición críticoreflexiva, que se consigue a través del ejercicio, no del diván pero si de la práctica propiciada en estas escuelas o a través de los consejeros.

\section{Conclusión}

El estoicismo puede ser pensado como una modalidad filosóficoterapéutica que tuvo en cuenta particularmente a la vejez. La misma permite un ejercicio crítico reflexivo, digamos terapéutico, que posibilitaría por un lado, que el sabio estoico soporte los desafíos clásicos de la cultura occidental, la enfermedad, la vejez y la muerte; y por el otro que encuentre en la vejez el esplendor del alma despojada de objetos "encadenadores" y permitan su mayor dominio. El viejo podría ser aquel

[...] que puede complacerse a si mismo, satisfacerse consigo mismo, poner en él toda su alegría y su satisfacción, sin esperar ningún placer, ninguna alegría, ninguna satisfacción distinta, ni de los placeres físicos de los que ya no es capaz ni de los placeres de la ambición, a los cuales ha renunciado. (FOUCAULT, 2002, p. 115).

El uso de escuelas y de consejeros permitía que este ejercicio no sea una pura consolación filosófica sino una verdadera práctica de transformación de la consciencia, que situaba un síntoma, la estulticia, y permitía a través de su terapéutica un fin, la sabiduría. Esta implicaba el regocijo consigo mismo, sin refugiarse en una búsqueda desenfrenada de objetos compensatorios así como comprender los límites sin quedar atemorizados, “[ ... ] devolviéndole a la naturaleza, en el momento de la muerte, todo lo que legítimamente le pertenecía a ella." (FERRATER MORA, 1944, p. 612). 


\title{
STOIC THERAPEUTIC WITH THE OLDNESS
}

\begin{abstract}
The new stoicism produced a vast theory to think the oldness from a positive and defiant angle to the considerations of this era. This has given place to a new life style in the oldness, called Ciceronian retirement, and produced a form of therapeutic that defined a symptom and a relief manner to face the changes that supposes the aging process. The research is based on literary sources, philosophical and historical.

Keywords: Old Age. Stoicism. Therapeutics.
\end{abstract}

\section{REFERÊNCIAS}

BRUN, Jean. El Estoicismo. Buenos Aires: Eudeba, 1968.

CICERÓN, Marco Tulio. De vrais biens et de vrais maux. In:

Oeuvres Complètes. París: Les Belles Lettres, 1961. P. 272-385.

CICERÓN, Marco Tulio. La vejez. Barcelona: Juventud, 1982.

ENGBERG-PEDERSEN, Troels. El descubrimiento del bien: oikéiosis y kathékonta en la ética estoica. In: SCHOFIELD, Malcom; STRIKER, Gisela (Org.). Las normas de la naturaleza. Estudios de ética helenística. Buenos Aires: Manantial, 2001. P. 152-190.

EPICTETO. Entretiens. Paris: Les Belles Lettres, 1950.

EPICTETO. Máximas. Madrid: Calpe, 1919. (Manuales Gallach)

FERRATER MORA, José. Diccionario de Filosofia. México: Atlante, 1944.

FOUCAULT, Michel. L'Herméneutique du sujet: cours au College de France, 1981-1982. Tlalpan: Fondo de Cultura Económica, 2002 
IACUB, Ricardo. Erotismo y vejez en la cultura greco-latina. Revista Brasileira de Ciências do Envelhecimento Humano, Passo Fundo, v. 2, n. 2, p. 84-103, jul.-dez. 2004.

MARCO AURELIO. Meditaciones. Libro II. Madrid: Biblioteca Clásica Gredos, 1987.

SÉNECA, Lucio Anneo. Carta LVIII. Libro Sexto. In: . Cartas Morales a Lucilo. Barcelona: Iberia, 1955a. P. 159-188. (Colección Obras Maestras)

SÉNECA, Lucio Anneo. Carta XXVI. Libro Tercero. In: Cartas Morales a Lucilo. Barcelona: Iberia, 1955b. P. 75-97. (Colección Obras Maestras)

SÉNECA, Lucio Anneo. Carta XCII. Libro Duodécimo. In: Cartas Morales a Lucilo. Barcelona: Iberia, 1955c. P. 69-102. (Colección Obras Maestras)

SÉNECA, Lucio Anneo. Carta LXXVI. Libro Noveno. In: Cartas Morales a Lucilo. Barcelona: Iberia, 1955d. P. 253-282. (Colección Obras Maestras)

SÉNECA, Lucio Anneo. Sobre la brevedad de la vida. In: . Diálogos. Barcelona: Altaya, 1997. P. 317-347.

SÉNECA, Lucio Anneo. Epístolas 12. Libro I. In: Cartas Morales a Lucilo. Madri: Editorial Biblioteca Gredos, 2000. P. 95-151.

TROYANSKY, David G. Miroirs de la viellesse... en France au siècle des lumieres. Paris: Eshel, 1992. 